\title{
Analgesic Plasma Concentrations of Oxycodone After Surgery for Breast Cancer - Which Factors Matter?
}

\section{Cajanus, Kristiina}

2018-04

Cajanus , K , Neuvonen , M , Koskela , O , Kaunisto , M A , Neuvonen , P J , Niemi , M \& Kalso , E 2018 , ' Analgesic Plasma Concentrations of Oxycodone After Surgery for Breast Cancer - Which Factors Matter? ' , Clinical Pharmacology and Therapeutics, vol. 103 , no. 4 , pp. 653-662 . https://doi.org/10.1002/cpt.771

http://hdl.handle.net/10138/325047

https://doi.org/10.1002/cpt.771

unspecified

acceptedVersion

Downloaded from Helda, University of Helsinki institutional repository.

This is an electronic reprint of the original article.

This reprint may differ from the original in pagination and typographic detail.

Please cite the original version. 
Analgesic plasma concentrations of oxycodone after surgery for breast cancer - which factors matter?

K Cajanus $^{1}$; M Neuvonen ${ }^{2}$; O Koskela ${ }^{2}$; MA Kaunisto ${ }^{3}$; PJ Neuvonen ${ }^{2} ;$ M Niemi $^{2 *}$; E Kalso ${ }^{1 *}$

(1) Department of Anaesthesiology, Intensive Care and Pain Medicine, University of Helsinki and Helsinki University Hospital

(2) Department of Clinical Pharmacology, University of Helsinki and Helsinki University Hospital, Finland

(3) Institute for Molecular Medicine Finland (FIMM), University of Helsinki, Finland

* equal contribution

\section{Correspondence to:}

Eija Kalso, Pain Clinic, Department of Anaesthesiology, Intensive Care, and Pain Medicine, Helsinki University Central Hospital P.O.B. 140, 00029 HUS, Phone: +358-9-47175885, Fax: +358-9-47175641, e-mail: eija.kalso@helsinki.fi

References: 43

Figures: 4

Tables: 3

Keywords:

Opioid, oxycodone, analgesic concentration, breast cancer surgery, pain, postoperative 


\section{Abstract}

We investigated factors affecting analgesic oxycodone concentrations after breast cancer surgery in 1,000 women. Preoperatively, we studied heat and cold pain sensitivities and anxiety scores. Postoperatively, rest and motion pain intensities were measured and intravenous oxycodone was administered until satisfactory analgesia. At this point, the mean oxycodone concentration (variation coefficient) was $33.3 \mathrm{ng} / \mathrm{ml}(66 \%)$, and it was 21.7 $\mathrm{ng} / \mathrm{ml}(69 \%)$ when the patient requested oxycodone again. At both time points, the concentrations varied $>100$-fold between individuals. The analgesic oxycodone concentration was increased by $21.3 \%$ per motion pain intensity score on a $0-10$ scale and by $22.3 \%$ if axillary clearance was performed instead of sentinel node biopsy $(P<0.001) .47$ women, older and less anxious than others $(P<0.01)$, required no oxycodone. Anxiety, age, chronic pain or preoperative pain sensitivity were not independently associated with the analgesic oxycodone concentration. CYP2D6 and CYP3A genotypes did not affect analgesic concentration or duration of analgesia. 


\section{Introduction}

Parenteral oxycodone is increasingly used worldwide. However, pharmacokinetic data of intravenous oxycodone in the management of postoperative pain are limited. ${ }^{1}$ The dose of oxycodone needed for satisfactory analgesia varies remarkably between individuals. ${ }^{2}$

Several factors can affect the need of oxycodone. Different types of surgery predispose patients to variable postoperative pain intensities depending on the tissue being operated and invasiveness of surgery. ${ }^{3,4}$ Moreover, high levels of anxiety associate with increased pain sensitivity and opioid requirement. ${ }^{4-6}$ Older age increases plasma oxycodone concentrations and lowers its dose requirement. ${ }^{7,8}$ This may be due to lower percentage of body water and to decreased liver and kidney function. ${ }^{8,9}$ In addition, chronic nicotine exposure may increase postoperative pain intensity and opioid consumption, possibly due to adaptive changes in the endogenous opioid system. ${ }^{10-12}$ Abstinent tobacco-smokers also require higher opioid doses postoperatively. ${ }^{13}$

Oxycodone is metabolized by the cytochrome P450 (CYP) enzymes CYP3A4/5 and 2D6 (Figure 1). The major pathway is N-demethylation by CYP3A4 to noroxycodone, which lacks opioid activity. ${ }^{14}$ Metabolism via CYP2D6 yields oxymorphone, which has a strong opioid potency, ${ }^{14}$ but its concentration remains very low. ${ }^{15}$ Further oxidation of both noroxycodone and oxymorphone results in noroxymorphone, which is a strong $\mu$-opioid receptor agonist, but does not penetrate the blood brain barrier and consequently has only peripheral effects. ${ }^{16}$ Ketone reduction yields two stereoisomers of oxycodol from oxycodone, noroxycodol from noroxycodone, and oxymorphol from oxymorphone. ${ }^{15}$ Oxycodone and its metabolites are excreted via kidneys, in unconjugated and conjugated forms. ${ }^{15,17}$ Inhibition 
and induction of CYP3A4 have had marked effects on plasma concentration of oxycodone, ${ }^{18,19}$ but inhibition of CYP2D6 or genetically poor CYP2D6 metabolism have only marginally increased oxycodone concentrations. ${ }^{20,21}$ In experimental pain models in healthy volunteers, CYP2D6 poor metabolizers (PM) experienced less pain relief with oxycodone than extensive metabolizers (EM). ${ }^{22}$ However, the same research group did not find any difference in the post-operative analgesic effect of oxycodone between these two CYP2D6 phenotypes. ${ }^{21}$

Variability in genes related to pharmacodynamics may also affect the efficacy of oxycodone. ${ }^{23,24}$ For example, the OPRM1 c.118A>G (rs1799971, p.Asn40Asp) single nucleotide variation (SNV) has been found to affect postoperative oxycodone consumption, but no studies have explored its effect on the required analgesic concentrations of oxycodone.

The analgesic oxycodone concentrations have been studied only in small samples $(\leq 50$ individuals) after abdominal surgery..$^{25-27}$ Our aim was to characterize analgesic plasma concentrations of oxycodone in 1000 women after breast cancer surgery, to find out how much they vary between individuals, and what factors explain this variation. This information could be valuable for the individualized management of postoperative pain and for future pharmacogenetic studies of analgesics.

We examined 1,000 Finnish women undergoing surgery for breast cancer. In the postoperative phase, plasma oxycodone and its main metabolite concentrations were measured when the patients considered their analgesia satisfactory for the first time by intravenous 
dose titration and when they requested a new dose of oxycodone. Various patient- and surgery-related factors as well as factors related to the pharmacology of oxycodone were analyzed in association to these oxycodone plasma concentrations. 


\section{Results}

\section{Oxycodone concentrations at the two time points}

Plasma concentrations of oxycodone and its metabolites at the first state of satisfactory analgesia were available from 938 out of the 1,000 patients. 399 patients did not require further oxycodone after having achieved satisfactory analgesia in the post-anesthesia care unit (PACU); therefore the concentrations were available from 539 patients at the latter time point. Their analgesic oxycodone concentrations did not differ significantly from those of the 399 patients who did not need a new dose of oxycodone after having achieved satisfactory analgesia. The patients who did not request more oxycodone were older (mean 58.8 vs. 55.3 years, $P<0.001)$ and had preoperatively less anxiety $(P<0.001)$ than the 539 patients who requested a new dose after satisfactory analgesia (Supplementary Table 1). 47 patients did not request any oxycodone in the PACU. They were significantly older $(P<$ $0.01)$, shorter $(P<0.01)$, and had significantly less preoperative anxiety $(P<0.01)$ than the other patients (Supplementary Table 2). As they were not given oxycodone, their data could not be used in other analyses. Furthermore, the concentration data at the first state of satisfactory analgesia were missing from 15 patients.

Oxycodone plasma concentrations needed for satisfactory analgesia varied greatly between individuals (range $<0.1-311 \mathrm{ng} / \mathrm{ml}$ ). The variation remained high (range $<0.1-191 \mathrm{ng} / \mathrm{ml}$ ) at the time point when the patient requested a new dose, i.e., on the average 162 min later. The plasma concentrations of both oxycodone and its metabolites correlated strongly between the two time points (Figure 2). 
Geometric means and geometric CV\%s (coefficient of variation) for oxycodone and metabolite plasma concentrations at the first state of satisfactory analgesia were: oxycodone $33.3 \mathrm{ng} / \mathrm{ml}$ (66\%), noroxycodone $1.46 \mathrm{ng} / \mathrm{ml}$ (106\%), oxymorphone $0.11 \mathrm{ng} / \mathrm{ml}$ $(110 \%)$ and noroxymorphone $0.26 \mathrm{ng} / \mathrm{ml}(150 \%)$. When the patient requested a new dose, the concentrations were: oxycodone $21.7 \mathrm{ng} / \mathrm{ml}$ (69\%), noroxycodone $3.67 \mathrm{ng} / \mathrm{ml}$ (73\%), oxymorphone $0.14 \mathrm{ng} / \mathrm{ml}$ (89\%), and noroxymorphone $0.67 \mathrm{ng} / \mathrm{ml}(92 \%)$.

The analgesic plasma concentrations of oxycodone correlated significantly with the weightadjusted total dose of oxycodone needed for the first state of adequate analgesia (Figure 3). Yet, the individual concentrations varied up to 4-fold after the same weight-adjusted total dose. The individual with the highest oxycodone concentration at both time points also had an exceptionally low dose/concentration ratio. We could not identify any obvious reason for these exceptionally high concentrations. Excluding her from the statistical analysis did not change the conclusions.

\section{Factors affecting analgesic oxycodone concentrations}

In a multivariate linear regression analysis, pain intensity after surgery and the type of surgery strongly associated with the analgesic oxycodone concentration. The analgesic oxycodone concentration increased by $21.7 \%$ (95\% Cl 17.5-26.1, $P<0.001)$ per one motion pain intensity score increase on a 0-10 Numerical Rating Scale (NRS) (Table 1). The 170 patients with high motion pain intensity scores (NRS 7-10) needed nearly two-fold higher plasma oxycodone concentrations (geometric mean $50.7 \mathrm{ng} / \mathrm{ml}$ ) than the 699 patients having moderate pain intensity (NRS 4-6; oxycodone $31.6 \mathrm{ng} / \mathrm{ml}$ ), and almost three-fold higher concentrations than the 59 patients with low postoperative motion pain intensity 
(NRS 0-3; oxycodone $17.8 \mathrm{ng} / \mathrm{ml}$ ) (Figure 4). The mean intravenous oxycodone doses needed for the analgesic concentrations in these three pain score groups were $0.18 \mathrm{mg} / \mathrm{kg}, 0.10$ $\mathrm{mg} / \mathrm{kg}$, and $0.07 \mathrm{mg} / \mathrm{kg}$, respectively (Table 2 ). The motion and rest pain intensities were in almost complete correlation ( $r=0.99)$ (Table 1.).

The plasma oxycodone concentration required for satisfactory analgesia was significantly higher (mean 23.4\%, 95\% $\mathrm{Cl} 12.1-36.0 \%, P<0.001$ ) in those who had removal of the axillar lymph nodes (axillary clearance, AC) compared with sentinel node biopsy only. In patients having undergone axillary clearance, the geometric mean plasma oxycodone concentration was $38.7 \mathrm{ng} / \mathrm{ml}$ (66\%) and in those having undergone sentinel node biopsy it was $29.6 \mathrm{ng} / \mathrm{ml}$ (62\%). The corresponding doses of oxycodone needed for these analgesic concentrations were $0.13 \mathrm{mg} / \mathrm{kg}$ and $0.10 \mathrm{mg} / \mathrm{kg}$, respectively. The type of breast surgery (breast conserving surgery/mastectomy) had no statistically significant effect on the analgesic oxycodone concentration (Table 1.). Also other patient characteristics (e.g., age, smoking or body mass index, preoperative anxiety, heat pain or cold pain sensitivity) showed no statistically significant effect on the analgesic plasma concentrations of oxycodone.

\section{CYP2D6, CYP3A4/5 and OPRM1 genotypes}

The CYP2D6 metabolizer status could be inferred from the genotype in 918 patients. There were 80 ultra-rapid metabolizers (UM), 799 extensive metabolizers (EM), 16 intermediate metabolizers (IM), and 23 poor metabolizers (PM). The genotype groups did not differ in regard to the demographic factors. Major differences were seen between the CYP2D6 genotype groups in the oxymorphone and noroxymorphone concentrations, both when the patients reported satisfactory analgesia for the first time and when they needed a new dose 
(Table 3). No significant differences were seen in the oxycodone or noroxycodone concentrations between the CYP2D6 genotypes. CYP3A4 rs35599367 ( ${ }^{*} 22$ allele) or CYP3A5 rs776746 (*3 allele) SNVs showed no significant effects on oxycodone or its metabolite concentrations at either of the two time points. Neither the CYP2D6 nor the CYP3A4/5 polymorphisms affected the duration of the analgesic effect, i.e., the time between satisfactory analgesia and the need for a new oxycodone dose. The OPRM1 c.118A>G genotype did not significantly affect the analgesic plasma oxycodone concentration. 


\section{Discussion}

To our knowledge, this is the largest study assessing analgesic oxycodone concentrations and factors affecting these in the immediate postoperative phase. The patient group was homogenous as it consisted of only female patients sharing the same ethnic background (Caucasians). The study showed that there is wide variation in the analgesic plasma concentrations of oxycodone after breast cancer surgery. The concentration ranged from 0 , i.e., no oxycodone needed, to $311 \mathrm{ng} / \mathrm{ml}$. Postoperative pain intensity and type of axillary surgery were the most important factors associating with the analgesic oxycodone concentration. Axillary surgery was associated with significantly more pain than sentinel biopsy. However, even in the axillary surgery group, some patients did not need any oxycodone in the PACU whereas some patients required high plasma oxycodone concentrations in the absence of axillary surgery.

\section{Type of surgery}

The type of surgery that is performed to operate breast cancer depends mainly on the cancer status. The patients may need either removal of the breast (mastectomy) or resection of part of it. In addition, sentinel biopsies are performed to confirm the presence or absence of metastasis in the axillary lymph nodes. Axillary clearance is related to a high risk of nerve injury, which has been reported to associate with more intense postoperative pain. In accordance with this, axillary clearance significantly increased plasma oxycodone concentrations needed for satisfactory analgesia compared with sentinel node biopsy. Evoked postoperative pain is usually more severe than pain at rest. We tested evoked pain by asking the patient to raise the arm ipsilateral to surgery. Even though pain on movement showed the most significant association with analgesic plasma oxycodone concentrations, 
also pain at rest was a good predictor. As the rest pain was in strong correlation with pain during movement, it was not entered into the linear regression model. When considering the association between type of surgery and analgesic oxycodone concentrations, it can be expected that even higher concentrations than those reported in the current study may be needed after more extensive surgery. In line with this, two recent studies of 50 patients each suggested that the average analgesic concentration after open abdominal surgery would be about $75 \mathrm{ng} / \mathrm{ml} .{ }^{27}$ Three small studies ( $\left.\mathrm{N}=22-23\right)$ have assessed the minimum effective analgesic plasma oxycodone concentrations after laparoscopic cholecystectomies. One reported that the mean analgesic plasma concentration is 45 or $50 \mathrm{ng} / \mathrm{ml} .{ }^{25}$ The second study suggested that depending on whether $1 \mathrm{~g}$ or $2 \mathrm{~g}$ of intravenous acetaminophen was co-administered, the analgesic plasma concentration of oxycodone would be $62 \mathrm{ng} / \mathrm{ml}$ or 70 $\mathrm{ng} / \mathrm{ml}$, respectively. ${ }^{26}$ The third study reported that the average analgesic concentration of oxycodone was $98 \mathrm{ng} / \mathrm{ml}$ or $80 \mathrm{ng} / \mathrm{ml}$ depending on whether $10 \mathrm{mg}$ or $50 \mathrm{mg}$ of intravenous dexketoprofen was co-administered, respectively. ${ }^{28}$ The preoperative analgesic in our study was $1 \mathrm{~g}$ acetaminophen orally.

\section{Pain sensitivity and anxiety}

Anxiety associates with pain sensitivity and fear of pain. ${ }^{6,29}$ Anxious patients expect to experience more pain and also report higher pain intensity in experimental pain tests, and in acute and chronic pain. In the current study, anxiety was not independently associated with postoperative analgesic oxycodone concentrations in the multivariate linear regression analysis. This may be partly due to the fact that our patients had, on average, relatively low levels of anxiety. It is also possible that the effects of anxiety on analgesic oxycodone concentration were conveyed through pain intensity scores in the regression analysis. 
Patients who did not need any oxycodone, or did not need further oxycodone in the PACU after having achieved satisfactory analgesia, had significantly less anxiety than patients who needed additional oxycodone.

Age

In the linear regression analysis, age was not significantly associated with the analgesic oxycodone concentration. However, patients who did not need any oxycodone were significantly older than those who did. This agrees with the reports that older patients have less postoperative pain. ${ }^{30}$ Similarly, those patients, who did not need further oxycodone in the PACU after having achieved satisfactory analgesia, were significantly older than those who did. Previously Kaiko et al. ${ }^{31}$ have reported higher age to be associated with increased sensitivity to oral oxycodone. The need of lower total doses of oxycodone by elderly patients has been related to a prolonged elimination of oxycodone. ${ }^{7}$

\section{Gender, OPRM1, and smoking}

All our patients were women. The results can therefore not be generalized to male patients. Kaiko et al. ${ }^{31}$ also reported that women are more sensitive to the effects of oral oxycodone than men. We have previously reported in this patient cohort that the OPRM1 c.118A>G polymorphism explained only $1 \%$ of the variance in the oxycodone dose needed for satisfactory analgesia. Only 35 patients were homozygous for the minor allele (GG) and on average they needed $30 \%$ more oxycodone for satisfactory analgesia. ${ }^{24}$ However, in the current analysis the $O P R M 1$ c. $118 \mathrm{~A}>\mathrm{G}$ polymorphism had no significant effect on the analgesic oxycodone concentration. Nicotine has analgesic effects and abstinent smokers request more opioids in the postoperative period than non-smokers. ${ }^{13}$ In the current study, 
however, tobacco smoking did not have a significant impact on analgesic oxycodone concentrations. This may be explained by the fact that less than $20 \%$ of the women smoked, and smoking was mostly occasional.

\section{Pharmacokinetic factors}

Our study was designed to focus on the analgesic oxycodone concentrations after initial titration to adequate pain relief attempting to minimize interference by pharmacokinetic factors. The brain and plasma concentrations of oxycodone have been reported to achieve equilibrium relatively fast, compared with morphine. The average transfer half-life from plasma to brain is $11 \mathrm{~min}$ for oxycodone, ${ }^{32}$ whereas it can vary from 1.6 to 4.8 hours for morphine. ${ }^{33}$ This difference may be due to an active transport of oxycodone through the blood-brain barrier into the brain. ${ }^{34,35}$ Preclinical studies suggest that the free brain concentrations of oxycodone could be clearly higher than those in plasma. ${ }^{36}$ This would suggest that the brain oxycodone concentrations are not directly commensurate to plasma concentrations, and that differences in the still unidentified transport protein could explain some of the variation in the analgesic plasma concentrations of oxycodone.

CYP2D6 genotype did not affect the analgesic oxycodone concentrations, but it was associated with metabolite formation. As expected, the concentrations of oxymorphone in the PM and IM patients were about one third compared with the UM patients. The effect of CYP2D6 genotype was also evident in the plasma noroxymorphone concentrations, particularly in the second plasma samples, where the UM patients had nearly 10 -fold higher noroxymorphone concentrations than the PM-patients. The high (7.6\%) frequency of the UM variants among the breast cancer patients corresponds well with the UM frequency of 
7.2\% in healthy Finnish subjects. ${ }^{37}$ The CYP2D6 status did not affect the time the patients remained satisfied with analgesia, which would indicate lack of significant analgesic contribution by the metabolites. This is also supported by the fact that when the patients requested a further dose of oxycodone, the oxycodone concentrations had decreased to an average of $21.7 \mathrm{ng} / \mathrm{ml}$ from the $33.3 \mathrm{ng} / \mathrm{ml}$ at the first state of satisfactory analgesia, whereas the concentrations of the metabolites had risen. CYP $3 A 4 * 22$ and $C Y P 3 A 5 * 3$ alleles did not show any significant effect on oxycodone or metabolite concentrations, possibly due to small effects or the low number of minor allele carriers.

\section{What does analysing analgesic oxycodone concentrations add to monitoring oxycodone}

\section{requirements?}

As measurement of central nervous system (CNS) oxycodone concentrations is rarely feasible, plasma oxycodone concentrations should be the most sensitive measure to assess the individual relationship between oxycodone and its analgesic effect. Fast development of equilibrium between CNS and plasma concentrations of oxycodone enables rapid titration to the analgesic effect and minimal interference by other pharmacokinetic factors. Thus, several factors of interest relating to the pharmacogenetics and the transporter systems relevant to oxycodone may be studied using analgesic oxycodone concentrations as a "phenotype".

To conclude, postoperative analgesic plasma oxycodone concentrations varied more than a 100-fold between individuals. The major factors predicting the analgesic oxycodone concentrations were immediate postoperative pain intensity and whether the patient had 
undergone axillary clearance or not. Estimation of immediate postoperative pain intensity is a clinically useful tool when predicting patient's oxycodone requirements. 


\section{Methods}

Our study population consisted of 1,000 Finnish women diagnosed with non-metastasized breast cancer who were to undergo surgery for breast cancer at the Breast Surgery Unit, Helsinki University Hospital, Helsinki, Finland, between August 2006 and December 2010. Exclusion criteria were bilateral or metastasized cancer and immediate breast reconstruction. Of the 1,536 eligible patients, 1,149 were asked to participate in the study. 126 patients declined and 23 were withdrawn due to contraindication to the anaesthesia protocol, violation of the study protocol, or change in the type of surgery or for logistic reasons. The study protocol has earlier been described in detail. ${ }^{5}$ The age distribution of the patients was: $\leq 40$ years (48), 41-60 years: (559), and 61-75 years: (393). No patient was taking strong opioids. Data on concomitant medications affecting the CYP3A/5 and CYP2D6 pathways are shown is Suppl. Table 3.

The Coordinating Ethics Committee (journal number 136/E0/2006) and the Ethics Committee of the Department of Surgery (148/E6/05) of the Hospital District of Helsinki and Uusimaa, and the Finnish Medicines Agency FIMEA had approved the study protocol. A written informed consent was obtained from each patient. After consent, demographic, medical and medication data were collected from all patients. The patients also filled the Beck Depression Inventory ${ }^{38}$ and the Spielberger State and Trait Anxiety Inventory ${ }^{39}$ questionnaires.

Before surgery, cold and heat pain sensitivities were assessed. In the cold pain sensitivity test, the patient immersed her hand into $40 \mathrm{I}$ of cold $\left(2-4^{\circ} \mathrm{C}\right)$ water (Julabo USA Inc, Allenton, PA). Pain intensity was recorded every 15 seconds using NRS 0-10, zero 
representing "no pain" and 10 "worst pain imaginable". The patients were advised to withdraw the hand from the water at any time when the pain felt intolerable. The maximum time was set to 90 seconds. The time the patients kept the hand in the water was recorded. Heat pain was assessed with a thermode $(16 \mathrm{~mm} \times 16 \mathrm{~mm})$ placed on the volar side of the forearm contralateral to surgery. The thermode (TSA-II, NeuroSensory Analyzee; Medoc Ltd, Ramat Yishai, Israel) was first heated to $43^{\circ} \mathrm{C}$ (control), and then to $48^{\circ} \mathrm{C}$ for 5 seconds. The patients were asked to assess the intensity of pain using NRS 0-10. Cold pain data were available from 900 patients only due to the unavailability of the test device in the beginning of the study.

Surgery was personalised according to the patient's wishes and the clinical characteristics of the tumor. Anesthesia was standardized. All patients were premedicated with peroral diazepam 2.5-15 mg and acetaminophen $1 \mathrm{~g}$. A venous blood sample was drawn for DNA analysis at the induction of anesthesia, which consisted of intravenous propofol and remifentanil. Before moving to the post-anesthesia care unit (PACU), all patients were given fentanyl ( $1 \mu \mathrm{g} / \mathrm{kg}$ intravenously, i.v.), ondansetron (4 mg i.v.), and dehydrobenzperidol (0.01 $\mathrm{mg} / \mathrm{kg}$ i.v.). In the PACU, the patients were immediately asked to assess their pain intensity during rest and motion before the first oxycodone dose. Motion pain was tested by asking the patient to raise $90^{\circ}$ her arm ipsilateral to the surgery. The research nurse asked the patients about rest and motion pain intensity every 5 min and administered them with 1-3 mg i.v. oxycodone if they reported NRS $\geq 3$. This was repeated until the patient indicated satisfactory analgesia, and the first blood sample for oxycodone and its metabolite determination was taken at this point. After this the pain scores were recorded every 15 min until the patient required a new dose. At this time point the time from the previous 
administration was recorded and the second blood sample was taken before the new dose was administered. After about 2.5 hours in the PACU, the patients were given a patientcontrolled analgesia (PCA) device and moved to the surgical ward.

\section{DNA extraction and genotyping}

DNA was extracted from peripheral blood using the Autopure LS automated DNA purification instrument (Gentra Systems Inc, Minneapolis, MN). All genotyping was done blindly to phenotype information. Patients were genotyped for 10 CYP2D6 SNVs and copy number variation using Taqman genotyping assays and a copy number assay targeting exon 9. ${ }^{37}$ CYP2D6 metabolizer groups were inferred from the genotype data using the activity score method. ${ }^{40}$ CYP3A4 rs35599367 (*22) was genotyped with a commercially available kit (C_59013445_10) and the CYP3A5 rs776746 (*3) was assessed with a custom Taqman genotyping assay. ${ }^{41}$ Sequenom MassARRAY and iPLEX Gold Single Base Extension chemistry (Sequenom, San Diego, CA) were used to genotype OPRM1 rs1799971. Results were confirmed using duplicates and positive and negative control samples in each DNA plate.

\section{Measurement of oxycodone and its metabolites}

Plasma concentrations of oxycodone and three of its metabolites were quantified using an API 3000 liquid chromatography-tandem mass -spectrometry system (Sciex Division of MDS, Toronto, Ontario, Canada) as described previously, from $0.5 \mathrm{ml}$ plasma samples (see Suppl. data 1). ${ }^{42}$ The method was validated according to the Food and Drug Administration guidelines. ${ }^{43}$ The lower limits of quantification for oxycodone and oxymorphone, and noroxycodone and noroxymorphone were $0.1 \mathrm{ng} / \mathrm{mL}$ and $0.25 \mathrm{ng} / \mathrm{mL}$, respectively. Interday coefficient of variation was below $15 \%$ for all analytes at relevant concentrations. 


\section{Statistical analysis}

The data were analyzed using SPSS Statistics version 22 (IBM, New York, USA). Oxycodone and its metabolite concentrations below the limit of quantification were replaced with half of the quantification limit, except for those patients who did not need any oxycodone and were excluded from the respective analyses. Oxycodone and its metabolite concentrations were logarithmically transformed before statistical analysis. Possible effects of the variables affecting plasma oxycodone concentrations were investigated using a stepwise, forward linear regression analysis. The tested variables included age, height, weight, lean body weight, body mass index (BMI), smoking status, preoperative anxiety, preoperative chronic pain condition, preoperative pain in the breast, OPRM1, CYP2D6 and CYP3A4 genotypes, surgery type (mastectomy/breast conserving and sentinel node biopsy/axillary clearance), preoperative cold and heat pain sensitivities, cold pain tolerance and postoperative rest and motion pain intensities. Statistical significance level was set at $P<0.05$ for entry into the model and $>0.10$ for removal. Possible effects of CYP2D6 genotypes on oxycodone metabolite concentrations were investigated with one-way analysis of variance as were the differences between postoperative pain intensity groups. The results are expressed as geometric means with geometric coefficients of variation or relative effects with $95 \%$ confidence intervals. Possible correlations of oxycodone and its metabolite concentrations between the two studied time points were investigated with the Pearson correlation coefficient. The differences between the 47 patients, who did not require any oxycodone, and the rest of the patients were investigated using independent sample T test for the continuous variables, Fisher's exact test for the surgery type and Pearson's chi-square for 
OPRM1 genotype. Same statistical tests were also used to determine differences between the 539 patients who required additional oxycodone in the PACU after first satisfactory analgesia, and the 399 who did not. P-values below 0.05 were considered statistically significant. 


\section{Study Highlights}

\section{WHAT IS THE CURRENT KNOWLEDGE ON THE TOPIC?}

Parenteral oxycodone is increasingly used for postoperative analgesia. Individual analgesic doses of oxycodone vary significantly.

\section{WHAT QUESTION DID THIS STUDY ADDRESS?}

We examined individual analgesic plasma oxycodone concentrations and factors affecting them in 1,000 women after breast cancer surgery.

\section{WHAT THIS STUDY ADDS TO OUR KNOWLEDGE}

The analgesic oxycodone concentrations varied more than 100 -fold. Postoperative pain intensity and type of axillary surgery markedly affected the oxycodone concentration required for satisfactory analgesia. Patients with the highest motion pain intensity (scores 710/10) need nearly three times higher plasma concentrations of oxycodone than patients with low (0-3) scores. Preoperatively assessed anxiety, heat or cold pain scores, or CYP3A, CYP2D6 or OPRM1 genotypes were not independently associated with the analgesic plasma oxycodone concentrations.

\section{HOW THIS MIGHT CHANGE CLINICAL PHARMACOLOGY AND THERAPEUTICS}

Postoperative motion pain intensity strongly predicts the oxycodone plasma concentration the patient will need for satisfactory analgesia. This information can be valuable for individualized postoperative pain relief and for the future design of pharmacogenetic studies on opioid analgesia. 


\section{ACKNOWLEDGMENTS}

The authors are grateful for the invaluable assistance by the research nurses Eija R. Ruoppa and Minna Kaiponen throughout the project.

This study was supported by grants from the Academy of Finland $(110489,217028,139795)$, Folkhälsan Research Foundation, Medicinska Understödsföreningen Liv \& Hälsa, Signe and Ane Gyllenberg Foundation, Helsinki University Central Hospital Research Funds (TYH2008225, TYH2010210, TYH2012212), European Union Seventh Framework Programme (FP7) under grant agreement no 602919.

\section{CONFLICT OF INTEREST}

Authors have no conflicts of interest.

\section{AUTHOR CONTRIBUTIONS}

Kristiina Cajanus: Analysed the data and wrote the manuscript

Mikko Neuvonen: Measured the concentrations of oxycodone and its metabolites

Outi Koskela: Performed CYP genotyping and analyzed the CYP genotype data

Mari Kaunisto: Performed OPRM1 genotyping and participated in data interpretation and writing of the manuscript

Pertti J. Neuvonen: Designed the research, supervised oxycodone analytics, and participated in data interpretation and writing of the manuscript

Mikko Niemi: Designed the research, designed and supervised the statistical analysis, and participated in data interpretation and writing of the manuscript 
Eija Kalso: Designed the research, supervised the study procedure and data collection and writing of the manuscript. 


\section{References}

1 Olkkola, K.T. \& Hagelberg, N.M. Oxycodone: new 'old' drug. Current Opinion in Anaesthesiology 22, 459-462 (2009).

2 Kalso, E., et al. Intravenous morphine and oxycodone for pain after abdominal surgery. Acta Anaesthesiol Scand 35, 642-6 (1991)

3 Chung, F., Ritchie, E. \& Su, J. Postoperative pain in ambulatory surgery. Surv. Anesthesiol. 42, 251 (1998).

4 Ip, H.Y.V., Abrishami, A., Peng, P., Wong, J. \& Chung, F. Predictors of postoperative pain and analgesic consumption: A qualitative systematic review. Anesthesiology 111, 657-677 (2009).

5 Ozalp, G., Sarioglu, R., Tuncel, G., Aslan, K. \& Kadiogullari, N. Preoperative emotional states in patients with breast cancer and postoperative pain. Acta Anaesthesiol. Scand. 47, 26-29 (2003).

6 Kaunisto, M.A., et al. Pain in 1,000 women treated for breast cancer: a prospective study of pain sensitivity and postoperative pain. Anesthesiology 119, 1410-1421 (2013).

7 Saari, T.I., Ihmsen, H., Neuvonen, P.J., Olkkola, K.T., \& Schwilden, H. Oxycodone clearance is markedly reduced with advancing age: a population pharmacokinetic study. Br. J. Anaesth. 108, 491-498 (2012).

8 Liukas, A., et al. Elimination of intravenous oxycodone in the elderly: a pharmacokinetic study in postoperative orthopaedic patients of different age groups. Drugs Aging 28, 41-50 (2011).

9 White, P., et al. Perioperative care for the older outpatient undergoing ambulatory surgery. Anesthesia \& Analgesia 114, 1190-1215 (2012).

10 Shi, Y., et al. Smoking and pain: Pathophysiology and clinical implications. 
Anesthesiology 113, 977-992 (2010).

11 Christiano, A.V., Pean, C.A., Konda, S.R. \& Egol, K.A. Predictors of patient reported pain after lower extremity nonunion surgery: The nicotine effect. lowa Orthop. J. 36, 53-58 (2016).

12 Chiang, H.L., Chia, Y.Y., Lin, H.S. \& Chen, C.H. The Implications of tobacco smoking on acute postoperative pain: A prospective observational study. Pain Res. Manag. 2016, 9432493 (2016).

13 Steinmiller, C.L., Diederichs, C., Roehrs, T.A., Hyde-Nolan, M., Roth, T. \& Greenwald, M.K. Postsurgical patient-controlled opioid self-administration is greater in hospitalized abstinent smokers than nonsmokers. Journal of Opioid Management 8, 227-235 (2012). 14 Thompson, C.M., Wojno, H., Greiner, E., May, E.L., Rice, K.C., \& Selley, D.E. Activation of G-proteins by morphine and codeine congeners: Insights to the relevance of $O$ - and $N$ demethylated metabolites at $\mu$ - and $\delta$-opioid receptors J Pharmacol Exp Ther 308, 547-554 (2004).

15 Lalovic, B., Kharasch, E., Hoffer, C., Risler, L., Liu-Chen, L. \& Shen, D.D. Pharmacokinetics and pharmacodynamics of oral oxycodone in healthy human subjects: Role of circulating active metabolites. Clinical Pharmacology \& Therapeutics 79, 461-479 (2006).

16 Lemberg, K., Siiskonen, A., Kontinen, V.K., Yli-Kauhaluoma, J. \& Kalso, E. Pharmacological characterization of noroxymorphone as a new opioid for spinal analgesia. Anesthesia \& Analgesia 106, 463-470 (2008).

17 Poyhia, R., Seppala, T., Olkkola, K. \& Kalso, E. The pharmacokinetics and metabolism of oxycodone after intramuscular and oral administration to healthy subjects. Br. J. Clin.

Pharmacol. 33, 617-621 (1992).

18 Nieminen, T., et al. Rifampin greatly reduces the plasma concentrations of intravenous 
and oral oxycodone. Anesthesiology 110, 1371-1378 (2009).

19 Gronlund, J., Saari, T.I., Hagelberg, N.M., Neuvonen, P.J., Laine, K. \& Olkkola, K.T. Effect of inhibition of cytochrome P450 enzymes 2D6 and 3A4 on the pharmacokinetics of intravenous oxycodone: A randomized, three-phase, crossover, placebo-controlled study. Clinical Drug Investigation 31, 143-153 (2011).

20 Grönlund, J., Saari, T.I., Hagelberg, N.M., Neuvonen, P.J., Olkkola, K.T. \& Laine, K. Exposure to oral oxycodone is increased by concomitant inhibition of CYP2D6 and 3A4 pathways, but not by inhibition of CYP2D6 alone. Br. J. Clin. Pharmacol. 70, 78-87 (2010). 21 Zwisler, S.T., Enggaard, T.P., Mikkelsen, S., Brosen, K. \& Sindrup, S.H. Impact of the CYP2D6 genotype on post-operative intravenous oxycodone analgesia. Acta Anaesthesiol. Scand. 54, 232-240 (2010).

22 Zwisler, S.T., et al. The hypoalgesic effect of oxycodone in human experimental pain models in relation to the CYP2D6 oxidation polymorphism. Basic \& Clinical Pharmacology \& Toxicology 104, 335-344 (2009).

23 Lötsch, J. \& Geisslinger, G. Are $\mu$-opioid receptor polymorphisms important for clinical opioid therapy? Trends Mol. Med. 11, 82-89 (2005).

24 Cajanus, K., Kaunisto, M.A., Tallgren, M., Jokela, R. \& Kalso, E. How much oxycodone is needed for adequate analgesia after breast cancer surgery: Effect of the OPRM1 118A>G polymorphism. The Journal of Pain 15, 1248-1256 (2014).

25 Kokki, M., Broms, S., Eskelinen, M., Rasanen, I., Ojanperä, I. \& Kokki, H. Analgesic concentrations of oxycodone: A prospective clinical PK/PD study in patients with laparoscopic cholecystectomy. Basic \& Clinical Pharmacology \& Toxicology 110, 469-475 (2012).

26 Kokki, M., Broms, S., Eskelinen, M., Neuvonen, P.J., Halonen, T. \& Kokki, H. The analgesic 
concentration of oxycodone with co-administration of paracetamol: A dose-finding study in adult patients undergoing laparoscopic cholecystectomy. Basic \& Clinical Pharmacology \& Toxicology 111, 391-395 (2012).

27 Choi, B., Lee, Y., An, S., Lee, S., Lee, E. \& Noh, G. Population pharmacokinetics and analgesic potency of oxycodone. Br. J. Clin. Pharmacol. 83, 314-325 (2017).

28 Piirainen, A., et al. A dose-finding study of dexketoprofen in patients undergoing laparoscopic cholecystectomy: A randomized clinical trial on effects on the analgesic concentration of oxycodone. Drugs in R \& D 15, 319-328 (2015).

29 Ploghaus, A., et al. Exacerbation of pain by anxiety is associated with activity in a hippocampal network. The Journal of Neuroscience 21, 9896-9903 (2001).

30 Gibson, S.J. \& Helme, R.D. Age-related differences in pain perception and report. Clin. Geriatr. Med. 17, 433-456 (2001).

31 Kaiko, R.F. Pharmacokinetics and pharmacodynamics of controlled-release opioids. Acta Anaesthesiol. Scand. 41, 166-174 (1997).

32 Olkkola, K.T., Kontinen, V.K., Saari, T.I \& KAlso E.A. Does the pharmacology of oxycodone justify its increasing use as an analgesic? Trends Pharmacol Sci. 34, 206-14 (2013).

33 Lotsch, J. Pharmacokinetic-pharmacodynamic modeling of opioids. J. Pain Symptom Manage. 29, S90-103 (2005).

34 Sadiq, M.W., Boström, E., Keizer, R., Björkman, S. \& Hammarlund-Udenaes, M. Oxymorphone active uptake at the blood-brain barrier and population modeling of its pharmacokinetic-pharmacodynamic relationship. J. Pharm. Sci. 102, 3320-3331 (2013). 35 Boström, E., Simonsson, U.S.H. \& Hammarlund-Udenaes, M. In vivo blood-brain barrier transport of oxycodone in the rat: indications for active influx and implications for pharmacokinetics/pharmacodynamics. Drug Metabolism and Disposition 34, 1624-1631 
(2006).

36 Okura, T., Higuchi, K. \& Deguchi, Y. The blood-brain barrier transport mechanism controlling analgesic effects of opioid drugs in CNS. Yakugaku Zasshi 135, 697-702 (2015).

37 Pietarinen, P., Tornio, A. \& Niemi, M. High frequency of CYP2D6 ultrarapid metabolizer genotype in the finnish population. Basic \& Clinical Pharmacology \& Toxicology 119, 291296 (2016).

38 Beck, A., Ward, C.H., Mendelson M., Mock J., Erbaugh J. An inventory for measuring depression. Arch. gen. Psychiatry 4, 561-571 (1961).

39 Spielberger, C.D., Lushane, P.R., Vagg, P.R., Jacobs, A.G. Manual for the State-Trait Anxiety Inventory (Form Y). In Consulting Psychologists Press, Inc, Palo Alto, 1983).

40 Gaedigk, A., et al. The CYP2D6 activity score: translating genotype information into a qualitative measure of phenotype. Clin Pharmacol Ther 83, 234-42

41 Kivistö, K., T., et al. Lipid-lowering response to statins is affected by CYP3A5 polymorphism. Pharmacogenetics and Genomics 14 , 523-525 (2004).

42 Neuvonen, M., \& Neuvonen, P.J. Determination of oxycodone, noroxycodone, oxymorphone, and noroxymorphone in human plasma by liquid chromatographyelectrospray-tandem mass spectrometry. Ther. Drug Monit. 30, 333-340 (2008). 43 FDA Guidance, CDER, Us Department of Health and Human Services, Food and Drug Administration, Center for Drug Evaluation and Research and Center for Veterinary Medicine (CVM). Guidance for the Industry. Bioanalytical Method Validation. May 2001 
Table 1. Factors affecting the plasma oxycodone concentration at the time point when the patient reported satisfactory analgesia for the $1^{\text {st }}$ time

\begin{tabular}{|c|c|c|c|c|}
\hline \multirow[b]{2}{*}{ Variable } & \multicolumn{4}{|c|}{ 95\% Confidence interval } \\
\hline & B & Lower & Upper & $p$ \\
\hline $\begin{array}{l}\text { Motion pain when the patient } \\
\text { received the } 1 \text { st oxycodone } \\
\text { dose (per } 1 \text { point on a scale } \\
\text { from } 0 \text { to } 10 \text { ) }\end{array}$ & $21.7 \%$ & $17.5 \%$ & $26.1 \%$ & $<0.001$ \\
\hline Axillary clearance (vs. SNB) & $23.4 \%$ & $12.1 \%$ & $36.0 \%$ & $<0.001$ \\
\hline Excluded variables & & Beta & & p \\
\hline Weight (kg) & & $-4.0 \%$ & & 0.21 \\
\hline Lean body weight (kg) & & $-2.4 \%$ & & 0.44 \\
\hline Anxiety (STAI) & & $2.5 \%$ & & 0.45 \\
\hline Mastectomy & & $4.0 \%$ & & 0.25 \\
\hline Age (year) & & $-4.3 \%$ & & 0.18 \\
\hline $\mathrm{BMI}\left(\mathrm{kg} \mathrm{m}^{-2}\right)$ & & $-3.4 \%$ & & 0.28 \\
\hline Preoperative chronic pain & ition & $-2.6 \%$ & & 0.43 \\
\hline Preoperative pain in the br & & $5.3 \%$ & & 0.11 \\
\hline Heat pain intensity (NRS) & & $4.8 \%$ & & 0.15 \\
\hline Cold pain intensity at $30 \mathrm{~s}$ ( & & $4.3 \%$ & & 0.20 \\
\hline $\begin{array}{l}\text { Time patients kept their ha } \\
\text { water (s) }\end{array}$ & ice cold & $-3.1 \%$ & & 0.34 \\
\hline $\begin{array}{l}\text { Pain at rest when the pati } \\
\text { 1st dose of oxycodone (NR }\end{array}$ & eceived the & $27.3 \%$ & & 0.25 \\
\hline Smoking & & $-1.4 \%$ & & 0.67 \\
\hline OPRM1 rs1799971 genotyr & & $1.8 \%$ & & 0.58 \\
\hline CYP2D6 genotype $\mathrm{e}^{\#}$ & & $-4.0 \%$ & & 0.21 \\
\hline CYP3A4 rs3559967 genoty & 22) & $5.7 \%$ & & 0.09 \\
\hline CYP3A5 rs776746 genotyp & & $3.5 \%$ & & 0.29 \\
\hline
\end{tabular}

Results were obtained using forward type linear regression. Excluded variables are phenotypes tested but determined insignificant.

$\mathrm{R}$ square for the model is 0.169

$\mathrm{R}$ Square $=$ coefficient of determination, Beta $=$ standardized coefficients for model, $\mathrm{B}=$ Increase in oxycodone concentration needed for satisfactory analgesia, SNB = Sentinel Node Biopsy, STAI = Spielberger State Anxiety Inventory, BMI = Body Mass Index, NRS = Numerical Rating Scale (0-10) \#Genotypes were ultra-rapid, extensive, intermediate and poor metabolizers 
Table 2. Types of surgery and analgesic oxycodone doses and concentrations by pain intensity score groups

\begin{tabular}{|c|c|c|c|}
\hline & NRS 0-3 $(n=59)$ & NRS 4-6 ( $n=699)$ & NRS 7-10 $(n=170)$ \\
\hline $\begin{array}{l}\text { Breast conserving surgery / } \\
\text { Mastectomy (\%) }\end{array}$ & 35 / 24 (59 / 42) & $452 / 247(65 / 35)$ & $91 / 79$ (54 / 46) \\
\hline $\begin{array}{l}\text { Sentinel node biopsy / Axillary } \\
\text { clearance (\%) }\end{array}$ & 38 / $21(64 / 36)$ & $410 / 289(59 / 41)$ & 73/97 (43 / 57) \\
\hline \multicolumn{4}{|l|}{$\begin{array}{l}\text { Total amount of oxycodone needed } \\
\text { by the } 1 \text { st state of satisfactory } \\
\text { analgesia }(\mathrm{mg} / \mathrm{kg})\end{array}$} \\
\hline Geometric mean (CV\%) & $0.07(73)$ & $0.10(62)$ & $0.18(48)$ \\
\hline Range & $0.01-0.3$ & $0.02-0.6$ & $0.03-0.6$ \\
\hline \multicolumn{4}{|l|}{$\begin{array}{l}\text { Plasma concentration at the } 1 \text { st state of } \\
\text { satisfactory analgesia }(\mathrm{ng} / \mathrm{ml})\end{array}$} \\
\hline \multicolumn{4}{|l|}{ Oxycodone } \\
\hline Geometric mean (CV\%) & $17.8(76)$ & $31.6(66)$ & $50.7(48)$ \\
\hline Range & $<2.1-95.4$ & $<0.1-311$ & $9.6-130$ \\
\hline \multicolumn{4}{|l|}{ Noroxycodone } \\
\hline Geometric mean (CV\%) & $0.8(129)$ & 1.3 (109) & $3.3(76)$ \\
\hline Range & $<0.3-8.4$ & $<0.3-16.5$ & $<0.3-20$ \\
\hline \multicolumn{4}{|l|}{ Oxymorphone } \\
\hline Geometric mean (CV\%) & $0.1(97)$ & $0.1(108)$ & $0.2(89)$ \\
\hline Range & $<0.1-0.5$ & $<0.1-1.1$ & $<0.1-1.2$ \\
\hline \multicolumn{4}{|l|}{ Noroxymorphone } \\
\hline Geometric mean (CV\%) & $0.2(124)$ & $0.2(144)$ & $0.5(127)$ \\
\hline Range & $<0.3-1.8$ & $<0.3-5.2$ & $<0.3-7.6$ \\
\hline \multicolumn{4}{|l|}{$\begin{array}{l}\text { Plasma concentration when the patient } \\
\text { needed a new dose }(\mathrm{ng} / \mathrm{ml})\end{array}$} \\
\hline \multicolumn{4}{|l|}{ Oxycodone } \\
\hline Geometric mean (CV\%) & $11.0(66)$ & $20.9(69)$ & $31.5(53)$ \\
\hline Range & $0.8-38.2$ & $1.1-191$ & $12.7-115.9$ \\
\hline \multicolumn{4}{|l|}{ Noroxycodone } \\
\hline Geometric mean (CV\%) & $2.1(90)$ & $3.5(69)$ & $5.6(62)$ \\
\hline Range & $0.5-12.6$ & $0.2-17.1$ & $0.5-19.3$ \\
\hline \multicolumn{4}{|l|}{ Oxymorphone } \\
\hline Geometric mean (CV\%) & $0.1(87)$ & $0.1(86)$ & $0.2(80)$ \\
\hline Range & $<0.1-0.5$ & $<0.1-1.4$ & $<0.1-1.5$ \\
\hline \multicolumn{4}{|l|}{ Noroxymorphone } \\
\hline Geometric mean (CV\%) & $0.4(93)$ & $0.6(90)$ & $1.0(79)$ \\
\hline Range & $<0.3-2.7$ & $<0.3-6.6$ & $<0.3-6.7$ \\
\hline
\end{tabular}

Type of surgery, total amount of oxycodone needed and the oxycodone and metabolite concentrations at the $1^{\text {st }}$ state of satisfactory analgesia in the patients who are divided into three 
groups based on the intensity of motion pain after surgery before the first dose of oxycodone was administered. Continuous variables are given as geometric means and ranges. Categorical variables are given as number of patients and percentages. NRS numerical rating scale.

$\mathrm{CV} \%=$ coefficient of variation

Table 3. Postoperative oxycodone doses and concentrations by CYP2D6 genotype

IM

EM

UM

$\mathrm{p}$

Total amount of oxycodone needed by the 1st state of satisfactory analgesia $(\mathrm{mg} / \mathrm{kg})$
Geometric mean (CV\%)
$0.09(73)$
$0.12(51)$
$0.11(66)$
$0.12(53)$

Duration of the analgesic effect

(min)

Geometric mean (CV\%) $85.4(118) \quad 130.0(86) \quad 67.3(121) \quad 62.3(121)$

Concentration at the 1st state of satisfactory analgesia ( $\mathrm{ng} / \mathrm{ml}$ )

\section{Oxycodone}

Geometric mean (CV\%)

Range

Noroxycodone

Geometric mean (CV\%)

Range

Oxymorphone

Geometric mean (CV\%)

Range

Noroxymorphone

Geometric mean (CV\%)

Range

$28.9(73)$

$1.0(112) \quad 2.0(86)$

$<0.1-8.7$

$0.05(58)$

$<0.1-0.21$

0.05 (103)

0.07 (107)

PM $(n=17)$

Concentration when the patient

needed a new dose $(\mathrm{ng} / \mathrm{ml})$

\section{Oxycodone}

Geometric mean (CV\%)

Range

$17.6(84)$

$6.3-73.3$

Noroxycodone
$38.8(48)$

33.0 (67)

40.1 (53)

$14.1-88.1$

$<0.1$ - 311

10.6 - 128

$<0.1-11.1$

$0.06(68)$

$<0.1-0.22$

1.3 (107)

1.8 (92)

$<0.1-20$

$0.1-13.4$

$<0.1-0.38$

IM $(n=4)$

0.11 (112)

0.17 (92)

$<0.1-1.7$

$<0.1-1.1$

23.8 (57)

$14.5-47.9$

0.17 (168)

0.26 (137)

$<0.1-7.6$

$<0.1-5.2$

0.003

0.374

0.962

$<0.001$ 


$\begin{array}{rccccc}\begin{array}{r}\text { Geometric mean (CV\%) } \\ \text { Range }\end{array} & 0.43-12.6 & 6.3(64) & 3.7(73) & 3.7(66) & 0.879 \\ \text { Oxymorphone } & & 3.52-13.8 & 0.17-19.3 & 0.57-14.2 & \\ \text { Geometric mean (CV\%) } & 0.06(56) & 0.09(36) & 0.14(88) & 0.22(75) & <0.001 \\ \text { Range } & <0.1-0.18 & <0.1-0.13 & <0.1-1.46 & <0.1-0.97 & \\ \text { Noroxymorphone } & & & & & \\ \text { Geometric mean (CV\%) } & 0.06(68) & 0.27(109) & 0.62(92) & 1.02(81) & <0.001 \\ \text { Range } & <0.1-0.23 & <0.1-1.2 & <0.1-6.7 & <0.1-5.1 & \end{array}$

$\mathrm{CV} \%$ = coefficient of variation

$\mathrm{PM}=$ poor metaboliser, $\mathrm{IM}=$ intermediate metaboliser, $\mathrm{EM}=$ extensive metaboliser, $\mathrm{UM}=$ ultra-rapid metaboliser 


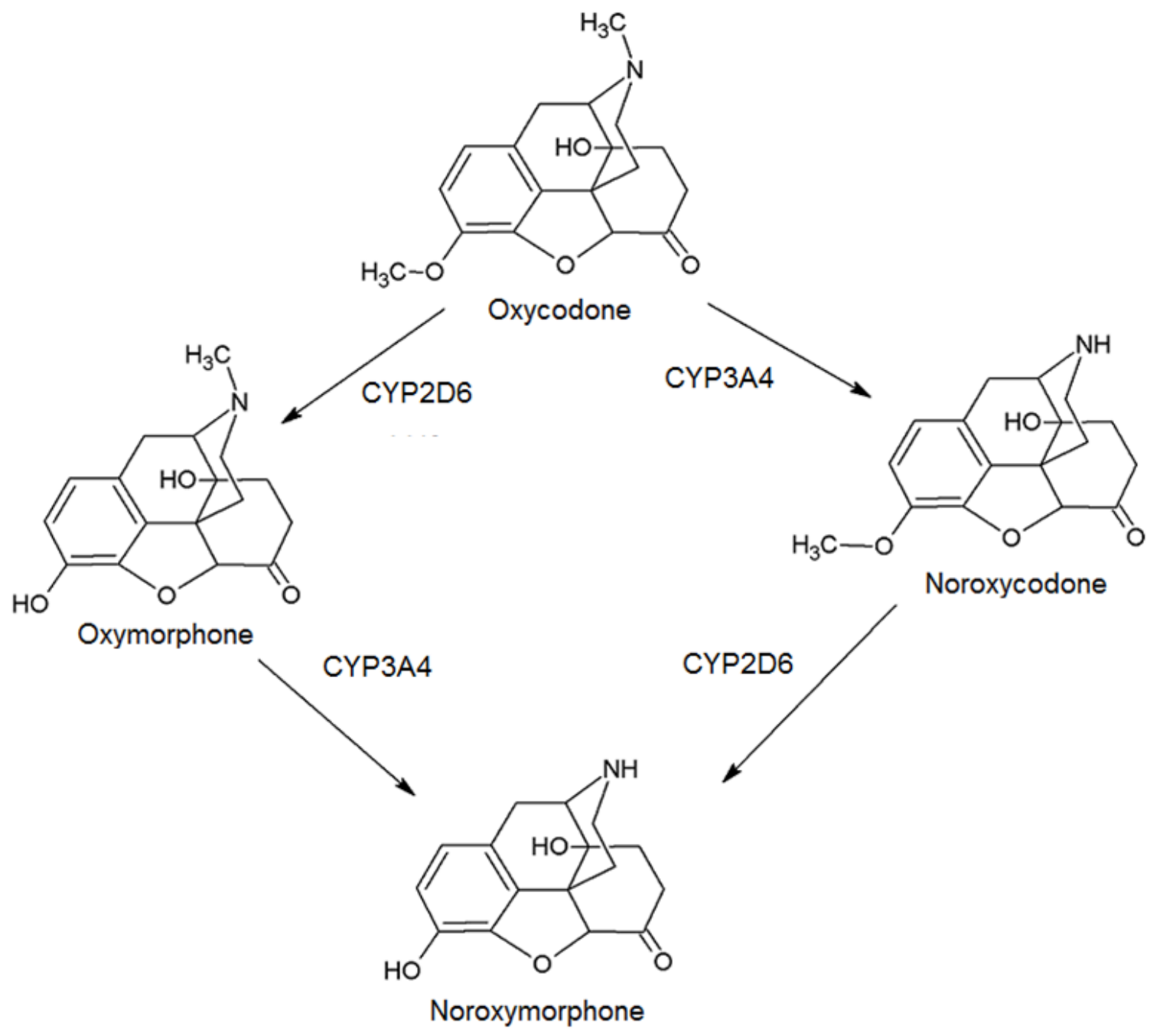

Figure 1. Main metabolic pathways of oxycodone. 

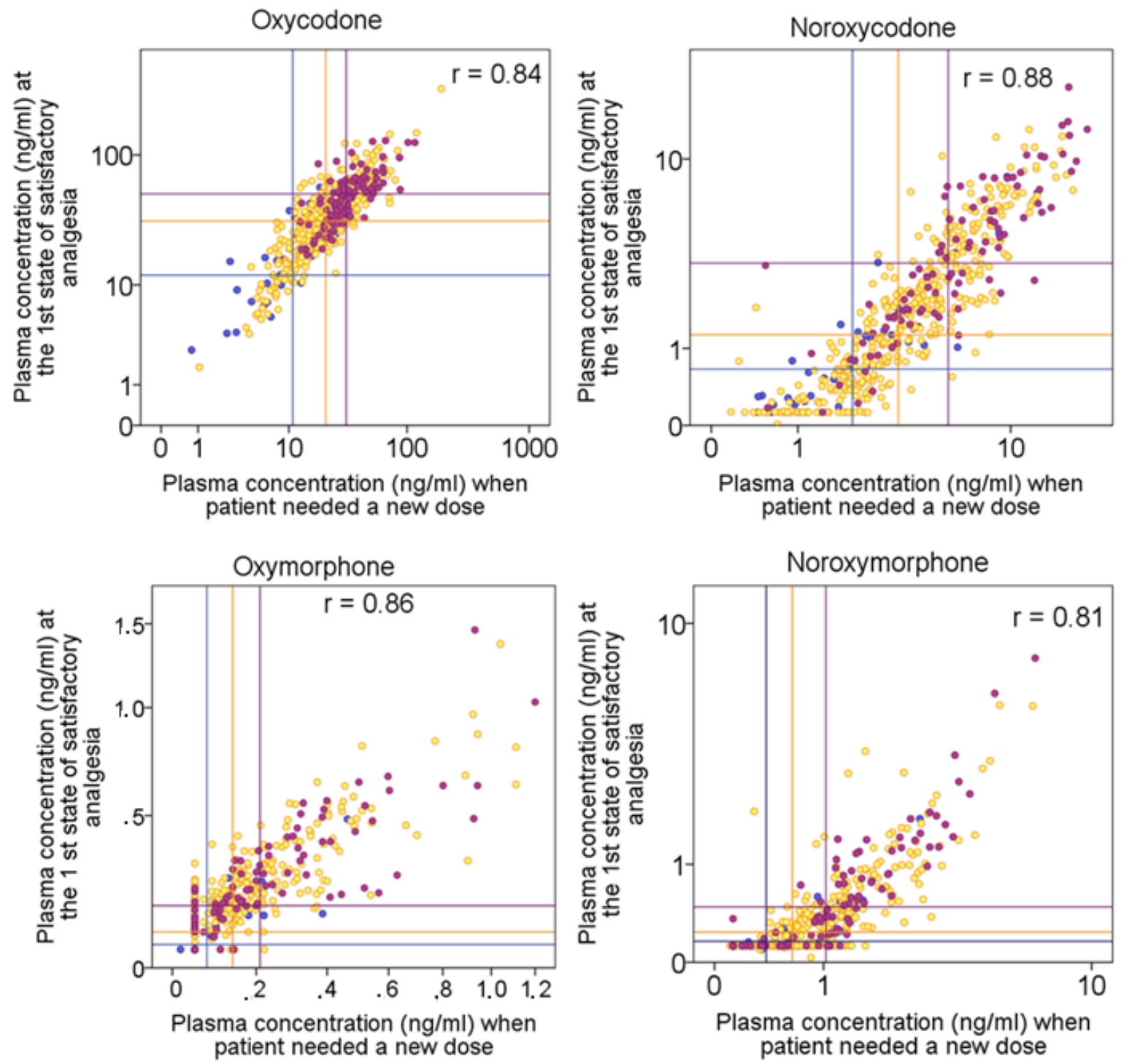

Motion pain intensity before the patient received the 1st oxycodone dose

ONRS $0-3$ NRS $4-6$ ONRS 7 - 10

Figure 2. Correlations between plasma concentrations of oxycodone and its three main metabolites at the two time points: when the patient indicated satisfactory analgesia for the first time ( $1^{\text {st }}$ state of satisfactory analgesia) and when the patient needed a new dose of oxycodone. The patients are divided into three groups based on the intensity of motion pain 
after surgery before the first dose of oxycodone was administered. The geometric mean of each group is given as a colored line. NRS = Numerical Rating Scale (0-10) of pain intensity.

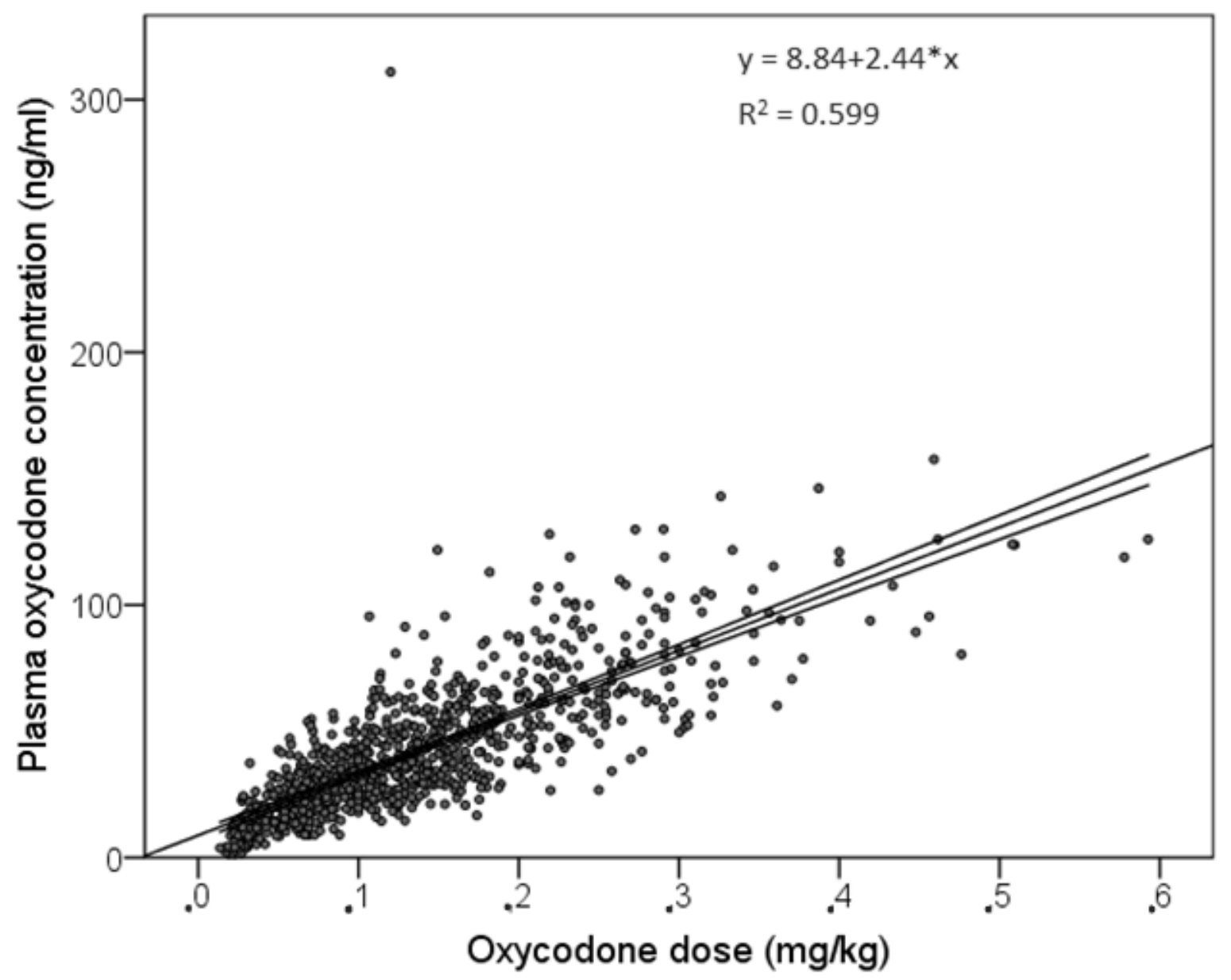

Figure 3. Correlation between oxycodone doses $(\mathrm{mg} / \mathrm{kg})$ and plasma concentrations $(\mathrm{ng} / \mathrm{ml})$ during the first state of satisfactory analgesia. 


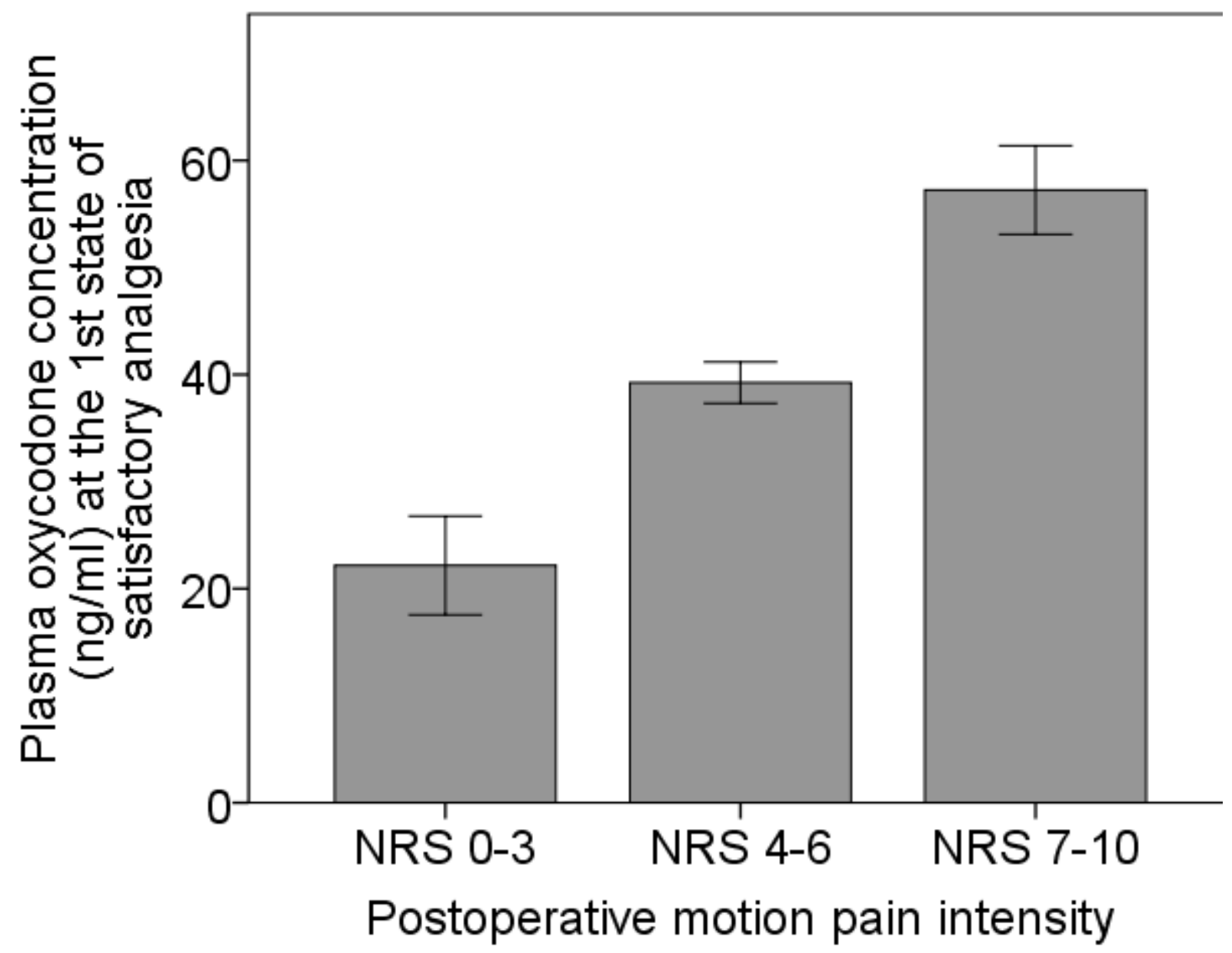

Figure 4. The arithmetric means (SD) of analgesic oxycodone plasma concentrations by postoperative motion pain intensity score groups. NRS = Numerical Rating Scale (0-10). 